\section{Valuing of knowledge in organizations and its embedding into organizational practices and routines}

\author{
Andréa Cherman \\ Sandra Regina da Rocha-Pinto \\ Pontifical Catholic University of Rio de Janeiro (PUC-Rio), IAG Business \\ School, Business Administration Department, Rio de Janeiro, RJ, Brazil
}

\begin{abstract}
Purpose - This study aims to analyze the impact of the different ways in which organizational members perceive and experience valuing of knowledge within the work context on its subsequent embedding into organizational routines.
\end{abstract}

Design/methodology/approach - The phenomenographic method was applied, using in-depth semi-structured interviews for data collection. The intentional sample comprised twenty-two human resource professionals.

Findings - The structural context, which the organization is part of, creates the social and spatial context that shapes a structuring pattern. This pattern establishes the way people consider knowledge of value and act to embed it into organizational practices and routines.

Originality/value - The study reveals the relevance of contemporary organizational structures and forms - cooperatives, hybrid and social business; holacratic or entrepreneurial models; collaborative or partnership networks for innovation - that promote the use and embedding of individual knowledge into organizational routines and practices.

Keywords - Valuing of knowledge; organizational knowledge; organizational routines; phenomenography
Received on

08/02/2016

Approved on

$15 / 06 / 2016$

Responsible editor:

PhD. J. Ignacio Canales

Evaluation process:

Double Blind Review

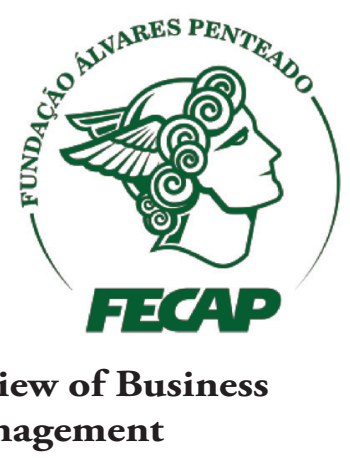

DOI: $10.7819 /$ rbgn.v18i61.2966 


\section{Introduction}

The area of organizational knowledge (OK) has been widely studied, stimulating a discussion on how individual knowledge becomes embedded in organizational knowledge (Gherardi, 2000; Orlikowski, 2002; Patriotta, 2003). The articles that explore OK point to the mechanisms used by individuals that intervene or bias the attribution of importance and valuation of certain types of knowledge to the detriment of others, and which influence the behavior of members in the subsequent incorporation of knowledge in the organization. In turn, studies on organizational routines (OR) are divided between the ones that analyze the capabilities that structure routines and those that study the practices that enact routines (Parmigiani \& Howard-Grenville, 2011), without, however, taking into account how the conception of knowledge of individuals considered relevant in that context influences the embedding of individual knowledge in organizational practices.

This study directly addresses the question of how individually valued knowledge is embedded and used in organizational routines and practices. It thus investigates behavior that results from adopting and internalizing what individuals consider the most valued specific knowledge into an organization. Hence, the objective of the study is to analyze how the different modes (conceptions) by which organizational members perceive and experience valuing of knowledge in the work context impact the subsequent embedding of that knowledge into organizational routines. To this end, a phenomenographic research was conducted (Akerlind, 2005; Marton, 1981; Marton \& Booth, 1997; Sandberg, 2000) with human resources (HR) professionals who, in principle, convey routines, culture, structure, strategies, organizational skills and trainingdevelopment-education, and who forge the vision of shared knowledge among the different groups of the organization.

Organizational knowing, in this paper, is defined by the perspective of knowing-in-practice and knowing-in-action, from the standpoint of practice-based theorizing, according to which knowledge results from work practice and is inseparable from the historical, social, spatial and temporal context experienced by individuals (Gherardi, 2000; Orlikowski, 2002; Patriotta, 2003). As an analogous theoretical vision, we adopt the stream of routines in practice, embedded through their execution, which feature both an ostensive and a performative character that results from a coordination that is fixed and undergoes continuous contextual adaptations and changes (Feldman, 2000; Feldman \& Pentland, 2003; Feldman \& Orlikowski, 2011; Pentland, 1995; Pentland \& Hærem, 2015). Based on this theoretical perspective and supported by phenomenography, the study focuses on knowledge of value and organizational routines expressed and perceived by individuals as being relevant according to their experience in a given context. However, no detailed analysis of organizational routines established a priori is performed; the study rather focuses on the behavior of individuals and the organization regarding the embedding of knowledge deemed important into organizational routines and practices.

This paper is divided into six sections: 1) introduction; 2) theoretical framework underlying the analysis; 3) method, including the details of its application; 4) findings of the empirical research; 5) discussion about the valuing of knowledge and its embedding into organizational practice and routines; 6) conclusions.

\section{Theoretical framework}

\section{I Organizational knowledge and value: definitions in the context of the study}

Views of organizational knowledge have been discussed by Gherardi (2000), Orlikowski (2002), and Patriotta (2003) and, according to them, its literature developed into three different lines. The first line treats knowledge as dichotomous, as a pre-existing 
object, independent of the knower, which can be retained and transferred from one mind to another (e.g., Nonaka, 1994; Nonaka \& Takeuchi, 1997). The second line, the structural or economic line, knowledge emerges as a factor of production, a commodity, reified into routines in the form of strategic capabilities, found in the resource-based view (Barney, 1991; 1996) and the knowledge-based view (Grant, 1996; Prahalad \& Hamel, 1990). The third line understands OK contextually, inserted in and emerging from organizational practice and action, where knowing and performing work in such a context are inseparable. This is the approach of knowingin-practice (Gherardi, 2000), knowing-in-action (Orlikowski, 2002), situated cognition and technical-scientific cognition (Patriotta, 2003), adopted as the theoretical foundation and for data analysis in this paper.

The three lines of OK presented in the paragraph above are not mutually exclusive, but are different approaches to the same subject: knowledge in organizations and ways to conceive it and treat it. The vision of knowing-in-practice and knowing-in-action, however, affords a synthetic approach, thereby making the historicalsocio-spatial-temporal context experienced by individuals inherent to and inseparable from the emergent knowledge (Antonacopulou, 2006; Brown \& Duguid, 1991; Gherardi, 2000; Latour, 2012; Lave \& Wenger, 1991; Orlikowski, 2002; Patriotta, 2003). The Sociology of Association or the Actor-Network Theory by Latour (2012), inserted into that view, underlies the explanatory dimension of the discussion in this study. According to that view, knowledge is relational, made up and mediated by human and nonhuman actors who form a social group, a collective arrangement. As for non-human actors, Latour (2012) presents all the mediating aspects that demand and compel human actors to act, such as organizational culture, decision/power structures, organizational practices and routines per se, and reification of 'leadership,' 'upper management,' 'strategy,' and 'hierarchy,' among others.

The author claims that although all actors - both human and non-human ones - are on the same plane and are the same size, some exert a greater collective weight due to the 'panorama' that conditions the actors' way of thinking and their justifications, but also due to the circulating 'structuring patterns' and the comparative 'scales' produced by the collective itself. The structuring pattern, panoramas and scales strongly establish the ways of thinking, acting and being that are part of the social structure. Any contextual change of that structure may alter these elements and everything it produces. Consequently, emergent knowledge is negotiated, contested, and always provisionally permanent until new knowledge come up as a result of a contextual change of the structure (Latour, 2012).

According to this perspective of knowingin-practice and knowing-in-action, value is defined as a collective sense of mutual appreciation. As such, it is socially constructed (Swart, 2011). Thus, in a specific context, a group assigns value to the result of a given activity (Swart, 2011). Through work practice, through action within a given context, the value of knowledge becomes visible to the members of that organization (Nag et al., 2007).

\subsection{Organizational routines}

Organizational routines go back to the work by Dewey (1922) on habit and reflexive action as the first guides for individual and collective behavior. Subsequently, Simon (1947), March and Simon (1958), and Cyert and March (1963) conceived OR as simple rules, a loosely agglutinated programming aimed at performance that enables the organization to react to the environment (March \& Simon, 1958), where standard procedures, rules and standards of behavior are developed to save time and to pay attention to certain aspects during decision making analysis (Simon, 1947).

However, Nelson and Winter (1982) definitively established the organizational routines, defined as patterns of regular and predictable organizational behavior, i.e., genes that define heritage and the exclusive distinction which organizations leverage for their evolutionary change. Additionally, routines are understood as: performance targets, promoting control mechanisms and the bases for replication; 
repositories of organizational memory, so that the organization prompts itself to trigger specific routines for specific individuals according to certain stimuli. Nelson and Winter (1982) reinforce the contextual character of routines, where skills, organization and technology are closely interconnected within a functional routine.

Pentland (1995) adds the perspective of practice to OR emphasizing daily actions associated with specific routines. The author introduces the notion of performative routines, which require that individuals make choices based on a large repertoire of possibilities; the resulting performance, on the other hand, is better conceived as an effort that is made as a result of the action. This perspective does not only take into account emergent routines that result from the performance of multiple actors (Feldman, 2000; Parmigiani \& Howard-Grenville, 2011), but also the generative ones, as they feature their own internal dynamics for their continuity and change (Feldman \& Pentland, 2003; Feldman \& Orlikowski, 2011).

Thus, although the initial concept associates the idea of OR to fixed, static, and repetitive rules and procedures that control activities and behaviors, the notion of OR evolved and as per Feldman (2000), routines incorporate continuous adaptations and changes into actions, into the practice of their execution, according to the context. These ideas resulted into two different constitutive lines of study as to what a comprehensive view of OR might be (Parmigiani \& Howard-Grenville, 2011).

The first line, the one of Capabilities, treats routines as a black box and analyzes them as a unique and complete entity; it focuses on the purpose and motivation of routines and on their impact on organizational performance. Individuals are considered rational to a limited extent, potentially acting in self-interest, but operating as expected and performing routines as they were designed.

A prototypical definition of the capabilities line is that routines are building blocks of capabilities, featuring a repetitive and contextdependent nature (Parmigiani \& HowardGrenville, 2011). According to this line, ORs are considered as (i) microfoundations of capabilities (Felin, Foss, Heimeriks, \& Madsen, 2012; Teece, 2007); repositories of organizational knowledge, which enables learning and change (Argote $\&$ Ren, 2012; Grant, 1996; Nelson \& Winter, 1982) and genes that may promote either stability or inertia (Szulanski, 1996). Blending the ideas about organizational learning and changes in OR led to the concept of dynamic capabilities (Eisenhardt \& Martin, 2000; Teece, Pisano, \& Shuen 1997; Zollo \& Winter, 2002), i.e., the systematic pattern of organizational activity aimed at generating and adapting operational routines (Zollo \& Winter, 2002). From this perspective, the fundamentals of changes in routines derive from mechanisms of learning from accumulated experience, articulation of knowledge and codification of knowledge in organizations.

The second line, the one of Practice, focuses on the internal dynamics of ORs, on their different parts and interconnections (Parmigiani \& Howard-Grenville, 2011), on the practice of routines, on how they operate and on how they are reproduced or changed according to how people enact them in the daily routine of organizations (Feldman, 2000; Feldman \& Pentland, 2003; Pentland \& Feldman, 2008). According to Feldman (2000), performative routines should be thought of as a flow that includes the broad range of thoughts, feelings and actions that individuals experience as they engage in work. In such a case, human action is situated in a specific set of circumstances, which may or may not lead individuals to perform the routines as they were designed.

ORs are mutually constituted by its ostensive aspects (routine internalized as a standard, its ostensive aspect being the abstract and general idea of standardized routine) as well as by its performative aspects (routine in practice, based on context, where the performative aspect consists of actions, enactments by people, at a specific time and place), where the former invokes 
the resources to perform the action and at the same time hampers and constrains routine changes, while the latter generates, recreates, maintains and modifies the ostensive aspect (Feldman \& Pentland, 2003; Pentland \& Feldman, 2008).

Friesl and Larty (2013) suggest that understanding OR according to the line of Practice allowed defining the replication of routines as a political process within organizations, since the notion of an agency encompassing individuals and their influences on practice (Latour, 2012) - and not only on institutions -, imply the multiple interests of the various actors engaged in routine. In their latest work, Pentland and Hærem (2015) expand the concept of ORs by defining them as standards of actions embedded in the socio-material context. They state that they can be represented as a network of actions performed by actors and artifacts (as understood by Latour, 2012). Based on this perspective, Bertels, Howard-Grenville and Pek (2016) found that organizational culture, understood as a repertoire/pattern of actions, shapes the routines and expectations that relate to them even before they are performed, which modifies them by excluding or including activities for their enactment. Thus, they corroborate the notion that the structural pattern by Latour (2012), shapes the way we think and act in each context.

\section{Method}

The phenomenographic method was used to find out how the subjects' conceptions of valuing knowledge in the work context impact its embedding in organizational routines and practices. Phenomenography aims to describe and map the qualitatively different ways of experiencing and apprehending a phenomenon (Marton, 1981; Marton \& Booth, 1997), seeking to understand how individuals perceive (awareness), make sense of (thought) and act (action) on specific aspects of their world. This awareness-thought-action triad is termed conception (Sandberg, 2000).

Phenomenography proposes the arrangement of conceptions - or descriptive categories - in a hierarchical, logic and inclusive structure of increasing complexity, which aims at relating the conceptions to each other. This structure is called an outcome space. As the individuals repeat their experience with the phenomenon under investigation, they become aware of new contours, expand their focal consciousness, shift from a narrow, limited, and incomplete conception of how to conceive the phenomenon to the next category, which is wider, more comprehensive and more complex than the previous one (Marton \& Booth, 1997). The totality of all ways of perceiving-thinking-acting the phenomenon, expressed by conceptions arranged in the outcome space, forms the collective mind (Marton \& Booth, 1997), i.e., the most complete consciousness possible of that phenomenon/reality.

To survey the conceptions of the subjects, the method requires applying 20 to 30 semistructured in-depth interviews. The purposive sample is planned by seeking variety in subjects, aiming to take into account the different ways of experiencing the phenomenon (Akerlind, 2005). For this study, interviews were conducted with $22 \mathrm{HR}$ professionals, considering (i) diversity of position (three levels - analyst, middle management, and senior management); (ii) professional experience (four ranges); (iii) type of company (national/multinational); (iv) company size (small/medium/large); and (v) training. The professionals surveyed ranged from analyst to vice president; they had from 3 to 36 years of professional experience and worked at 22 different companies, 12 of which were domestic and 10 of which were medium to large multinationals operating in 18 different sectors, i.e., perfumes and toiletries, food and drinks, pharmaceuticals, oil, gas and energy, telecommunication, information technology, insurance and pension plans, consulting and auditing, infrastructure and engineering, higher education, clothing manufacturing, retail trade of various kinds, e-commerce, and franchising. Figure 1 shows the planned and the obtained samples.

The phenomenographic interview is preceded by (i) the scenario, which clarifies and defines the topic of conversation to prevent topics 
that are not related to the survey scope from being introduced at the time of interview; (ii) the central question that requires that the subjects narrate their experience that best exemplifies the phenomenon, supporting questions, such as 'what' 'how' and 'why' to find out what the phenomenon is and how it is conceived, as well as understanding the perception and the thinking behind the action (Sandberg, 2000). The script included two central questions: "1) Could you give me an example of a situation in which you believed your knowledge was more (less) valued in the context of work?" After exploring the support questions as well, the next question was: "2) How do you perceive that valued knowledge is embedded into work practice and routines?"

The phenomenographic method qualitative and interpretative - doesn't operate with definitions of the nature of knowledge, neither with types of routines established a priori. The experiences that signify valued knowledge just as the perceptions of how such knowledge of value was embedded in the routines and practices of the organization - emerged from the narratives of the subjects, reinforcing the individuals' perspective on what was considered relevant and therefore valued in their work environment/context.

The interviews were conducted from November 2012 to March 2013. The total data collected amounted to a net of 21 hours and
9 minutes of recorded material (excluding the informed consent and the research scenario), which was transcribed for analysis, resulting in 352 pages. According to the method recommendations, the interviews were read entirely three times to separate the most dissimilar ones and group the most similar ones according to the meaning of the phenomenon. The goal was to isolate the aspects that would show the logical, hierarchical and inclusive interrelation between an appropriate number of conceptions. Only then was the content of each interview analyzed by means of Atlas-Ti to codify the elements found in the narratives, rearrange and confirm the conceptions and describe the descriptive category.

It is worth noting that the routines that emerged from the narratives by the HR professionals contained information on HR subsystem routines, such as recruitment and selection, attracting and retaining talents, training, granting of benefits, evaluation and performance assessment processes. The subjects further mentioned complex processes of setting up or shutting down plants and closing of departments and areas, and the ensuing employee relocation policies. This diversity and variation of complexity in organizational practices and routines is reflected by the different gradations of conceptions through which the subjects conceive knowledge of value in organizations.

\begin{tabular}{|c|c|c|}
\hline Groups & Variation Proposed in the Number of Respondents & Variation Obtained in the Number of Respondents \\
\hline $\begin{array}{l}\text { Length of Career to } \\
\text { Date }\end{array}$ & $\begin{array}{l}4 \text { subgroups containing } 5 \text { to } 8 \text { respondents: } \\
\text { - up to } 5 \text { years } \\
\text { - } 6 \text { to } 15 \text { years } \\
\text { - } 16 \text { to } 25 \text { years } \\
\text { - } \text { more than } 26 \text { years. }\end{array}$ & $\begin{array}{l}\text { - less than } 5 \text { years: } 4 \\
\text { - } 6 \text { to } 15 \text { years: } 8 \\
\text { - } 16 \text { to } 25 \text { years: } 7 \\
\text { - } \text { more than } 26 \text { years: } 3\end{array}$ \\
\hline Position / Title & $\begin{array}{l}\text { - } \text { analyst/coordinator: } 6 \text { to } 8 \\
\text { - middle management: } 8 \text { to } 12 \\
\text { - } \text { senior management/leadership: } 6 \text { to } 8\end{array}$ & $\begin{array}{l}\text { - } \text { analyst/coordinator/specialist: } 9 \\
\text { - middle management: } 8 \\
\text { - } \text { senior management/leadership: } 5\end{array}$ \\
\hline Type of Company & $\begin{array}{l}\text { Private National and Multinational Industries in } \\
\text { various economic sectors } \\
2 \text { subgroups: } \\
\text { - small and midsize companies: } 6 \text { to } 10 \\
\text { - large companies: } 10 \text { to } 14\end{array}$ & $\begin{array}{l}\text { - } 18 \text { industries } \\
\text { - } \text { National: } 12 \\
\text { - } \text { Multinational: } 10 \\
\text { - } \text { Midsize companies: } 8 \\
\text { - Large companies: } 14\end{array}$ \\
\hline Education & $\begin{array}{l}\text { - Business Administration: } 6 \text { to } 8 \\
\text { - Psychology: } 6 \text { to } 8 \\
\text { - Economics, Engineering, other: } 8 \text { to } 12\end{array}$ & $\begin{array}{l}\text { - Business Administration: } 6 \\
\text { - Psychology: } 9 \\
\text { - Economics, Engineering, other: } 7\end{array}$ \\
\hline
\end{tabular}

Figure 1. Demographic Variation of Purposive Sample (prepared by the authors) 


\section{I Field data analysis}

This study aimed to analyze how the different modes (conceptions) through which organizational members perceive and experience the valuation of knowledge in the context of work impact the subsequent embedding of knowledge into organizational routines. Based on their experiences and in the form of narratives, individuals reflected on knowledge of value and how it was embedded in (or excluded from) work routines. Some of these concerned human resources routines and their subsystems, while others concerned the routines and practices of the organization, in which HR intervenes through training, hiring, relocation or retention. Given the different conceptions of the phenomenon, different conceptualizations as to what organizational routines in fact are were also stated.

The analysis yielded five conceptions of valuing knowledge in the work context, i.e., five modes via which individuals perceive, attribute meaning to and behave towards valuing of knowledge at work, from the narrowest and most limited one to the widest and most complex one: Application to Work, Consideration of the Work-Individual, Self-realization at Work, Transformation of Work and the Individual, Emerging Creation for Life. These conceptions resulted from narrative elements, such as: the nature of knowledge, the dimension of social interaction of the individual with groups in relation to the phenomenon, social, spatial and temporal context, organizational structural arrangement, the role of routines, and the embedding through OR of knowledge valued by the individual into organizational knowledge.

Four conceptualizations of organizational routine also emerged, revealing that the subjects have different concepts of OR as a result of their experiences: Compliance routine, Certainty routine, Translated routine ('tropicalized' was the term originally obtained by the in-vivo code) and Innovation routine. Its constituent elements refer to: structuring the activity or task (to what extent it is new or routinized, to what extent it is formalized and disseminated), its flexibility (to what extent the routine may be altered and to what degree), the larger context of routines (their purpose, application and use). It should be noted that the conceptualizations regarding ORs were not grouped into descriptive categories, since they were explored as an aspect related to the use of valued knowledge in the work context. The conceptualizations belonging to organizational routines emerging from the interviews were rich, which shows to what extent perceptions may vary regarding a single phenomenon.

\subsection{Conceptions of valuing of knowledge in the context of work}

\subsection{Valuing knowledge means applying it at work}

Organizational knowledge is framed by the metaphor of the machine, which is part of the economic perspective (Gherardi, 2000) and the structural perspective (Patriotta, 2003), where knowledge of value is an object that supports the efficiency and effectiveness of organizational processes. Valued knowledge is expressed as something fundamentally individual and technical, it arises from formal education of individuals and from formal training received at work. It is useful insofar as it can be applied and yield the desired results for the organization.

Valuing of knowledge is presented as a depersonalized phenomenon, free of any human element; value is attributed by "culture", "values", and "planning" (Informant 8); "it's the chain, the strategies that tell you what is important" and "planning" (Informant 3); "Organizational routines" (Informant 22). Thus, the dimensional perspective of the phenomenon centers on the organization. Respondents answer with its voice, which shows to what extent the organization has been reified. Subjects rather avoid to place themselves in action, they prefer to refer to their actions using the third person. (e.g., "HR did ...", "the organization believes that...", "the culture 
values ...") or the first person plural [we (the organization and I) did ...].

The ORs structure the tasks (influential factor for valuing knowledge) and organize the life of the organization. For the HR area, 'routines establish work standards' (Respondent 3), 'make the rules transparent' (Respondent 22 ), thereby creating a sense of justice and justification regarding the organizational demands and responses. In a wider sense, they have a coordinative, delimiting and standardizing meaning and mainly meet the classification of the most evident routines by Feldman and Pentland (2003).

In addition, routines are given and predefined by the headquarters of the organization. They are about (i) compliance (regulatory rules and standard operating procedures to comply with regulatory agencies, ISO-type, and Good Practice certifications) and (ii) certainty (work policies, rules and procedures). At most, the certainty routines may be adapted, i.e., adjusted and made to fit to comply with legal, operational and local business demands and requirements.

Given the fact that valued knowledge is individual, technical and formal, embedding it into routines either reinforces the existing process or supports the adaptation of routines. As a matter of fact, in this category, the question is inverted, i.e., the established routines define work and therefore establish the knowledge of value that needs to be recruited, trained and aligned with each part of the process. In Latour's (2012) view, the routine defines how the subjects are supposed to perform their activities (Pentland \& Hærem, 2015) by outlining how they should behave and what they should value.

It may be inferred that embedding individual knowledge into organizational knowledge, into its practices and routines, is quite limited and utilitarian: its goal is rather adaptive than innovative. Individuals continually reproduce the organization in a mimetic fashion, rarely question it, nor do they take any personal or professional risks, which reiterates the political domination that routine may exert, preventing diversions and replicating and disseminating the values and beliefs of the dominant groups (Friels \& Larty, 2013).

\subsubsection{Valuing of knowledge is giving the work-individual due consideration (recognition)}

Valued knowledge is mainly individual, strongly based on formal and technical knowledge and practical experience; its main purpose is to be applied and to yield results at work. What differs from the previous conception is the respondents' need to get recognized by other organizational members. Consideration/recognition comes in different types of rewards, such as being mentioned in relation to a successful activity, being recommended/remembered to participate in or lead a specific job, or even getting a raise or a promotion.

Valuing of knowledge occurs in the form of individuals being recognized by the leader of the organization, by the leadership, peers and team members, i.e., valued knowledge is signified as given due consideration to individuals and/or their work and/or their knowledge - elements that are almost inseparable. A circular action seems to take place: the individual needs to be acknowledged by other members, his work/knowledge needs to be recognized so that he may value himself and he reflexively acts to have/be the knowledge that the organization values, in a process of adaptation and fitting into the organization. Within that circle, as the organization recognizes the individual's knowledge, as applied to work, he is understood as being of value for the company. The subject needs approval to feel that he belongs to the organization.

The processes and practices that are structured through ORs (endorsed by the leader) are designed to measure and control tasks, people and performance, so as to reproduce the recognition system rather than produce results in terms of quality of the activity's result. Organizations based on traditional (hierarchical, 
rigid) and/or familiar structures that feature a high degree of centralized decision-making and power and few formal processes seem to favor this type of conception.

Organizational routines structure and shape work and aim to control tasks, people and performance (Pentland \& Hærem, 2015). They make up certain routines, which are more expressive in nature (Pentland and Feldman, 2003). Given the adjustment and reflective act between subject and organization, the individual's knowledge is at the service of creating ORs (subject to approval by the leader or upper management), which set up control mechanisms that aim to evaluate performance and reward other employees. In other words, a new reflective cycle/ circle characterized by subjects relying on their conception that is applied to other employees. At the same time, ORs create and preserve the social status and recognition of subjects. It somehow seems that embedding individual knowledge into organizational knowledge (into practices and routines) is mediated by the leadership or upper management.

\subsubsection{Valuing of knowledge is self- realization at work}

This conception is based on the view that knowledge emerges from social practices in the context of work, i.e., the perspective of knowingin-practice (Gherardi, 2000) and knowing-inaction (Orlikowski, 2002), within the domain of located cognition (Patriotta, 2003). Valued knowledge is the result of sharing, of building by working collectively; it emerges from the situation that requires it. It is a blend of individual knowledge of diverse order and nature that are considered equally relevant: technical knowledge (from different operational and managerial areas), practical and relational experience.

Social exchange synthesizes individual knowledge into a solution that is wider than the initial individual proposals and therefore of greater value. For individuals, knowledge only acquires meaning when it is shared: “it doesn't make the slightest sense for me to know for myself" (Respondent 10). This concept refers to the vision of a community of practice, as described by Brown \& Duguid (1991) and Lave \& Wenger (1991). At the moment of sharing, knowledge becomes meaningful and hence valued, which reminds us of Swart's (2011) definition according to which value emerges from action and finds support and common collective meaning in that group (although the common meaning arising from actions takes place in all categories).

Knowledge of value emerging from shared construction should yield results that add to both collective, participatory work and to autonomous work, resulting in the individual's self-realization. The ORs are the consequence, the product of work, they result from practice and are then formalized and institutionalized inside the organization; they also undergo changes as new needs are identified during the performance of activities. Thus, the routines are created the way things are done, taking into account the implicit cultural rules (Bertels, Howard-Grenville \& Pek, 2016). They blend in with the concepts of routine innovation, since they are flexible, situationally adapted and strongly performative (Feldman \& Pentland, 2003).

Routines rather strive to be records for the conservation and dissemination of a proven practice (i.e., the result of something known and valued by individuals collectively) than to merely coordinate work. However, some processes established that way also serve to evaluate individual performance and may therefore be construed as goals. It is suggested that the embedding of individual knowledge in organizational knowledge through practices and routines is a fluid feedback process.

\subsubsection{Valuing knowledge is transformation of work and the individual}

This conception addresses the antagonism between valued knowledge as established by the individual - which enables the transformation of the organization, but questions its status quo 
- and the exercise of control based on formal, structural, organizational power and/or hierarchy and usually performed by the leader, manager or "hierarchical box" that holds such power. Just as in the previous category, the nature of valued knowledge is a collective construction shared between members and teams in the act of working. However, this is not processed in that collective and shared form inside the organization.

The question concerns the structures of power and hierarchy that present barriers to individuals, leading them to eventually question the organization itself: management and leadership, the mechanisms of power, the hierarchical structure, the very culture itself (cf. the 'non-human mediators' by Latour 2012; Pentland \& Hærem, 2015). As a result, the mode of making knowledge emerge is contested and conflictual among groups or members, as it questions the status quo and the existing structures. Valued knowledge needs to be transformed by the organization in order to be established. Established knowledge is contested, which reflects in a momentum that strengthens the relations of power.

As they work in such a conflicting context, individuals express the articulated political strategies to perform activities and/or to make sure their knowledge is taken into account. Thus, among other strategies, they cultivate relationships with people from other areas (Respondent 21 ), align with the immediate management in terms of conduct and the respective discourse of a given activity (Respondent 21), they make sure they are getting heard by the leader in power (interviewed 14). As a result of forging strategies, creating characters and performing roles (which the subjects deem necessary to avoid going unnoticed in such an environment), they transform themselves.

ORs are highly structured, either by formalization of the processes, or by internalization of the practices of the organizational culture. In some way or another, the working manner already exists, it is a given (Pentland \& Hærem,
2015). Thus, they are routines of certainty. Flexibility in practices and routines only occurs via determination of those in power or who hold a position backed by their office - not necessarily to change routines, but rather to meet someone's specific need or because the leader "said so." Such flexibility refers to the dispute discussed by Friel and Larty (2013).

The contribution of individual knowledge to organizational knowledge through practices and routines is low, unless contributing is a requirement of the job/position or arises from a request made by a leader, which results in much frustration and questioning from the subjects. Innovative projects are devalued and new ways of doing something established are not accepted, much less embedded in work practices or routines.

\subsubsection{Valuing knowledge is emerging creation for life}

This concept shows how disconnected valued knowledge is from the knowledge valued by the organization; these are separate and independent spheres. Valued knowledge provides a new paradigm, questions work itself and its objectives, deconstructs order and - as a longterm construction - provides innovation. On the other hand, knowledge valued by leaders, supervisors or upper management provides shortterm results in compliance with the organizational goal and reproduces the organization.

Knowledge emerges from practice and action (Gherardi, 2000; Orlikowski, 2002): it is generative, shared, and collective in the action of working, thereby composing the social context. It is located in people, in daily activities - both small and large - of work. Individuals seem to realize that there are new and different models for performing the conventional. However, to develop them, individuals must break paradigms and expose themselves to personal risk. Moreover, they act independently in the decision as to whether to expose themselves to such a risk.

Different from previous conceptions is the fact that individuals conceive themselves as 
different from the organization, i.e., they feel some kind of 'otherness' towards the organization, but which doesn't result in any clashes. Although they may question the organization, they don't seek to transform neither the company, nor themselves. Work is just part of life, not life itself. Valued knowledge is something that the subject carries throughout and for life, it is greater than the knowledge used at the organization. All these aspects are present in the focal consciousness of individuals (Marton \& Booth, 1997) and represent the broadest conception of the phenomenon.

ORs appear to be non-existent, inadequate or insufficiently structured for a given process, issue or situation. Thus, little experience in the situation and dynamics of the environment call for an experiment, approved by upper management, that allows the individual to create something different from the conventional with a high degree of autonomy. The solution sought is an emergent generative creation of work that intrinsically challenges the conventional order of how things are done. There is, therefore, room for trial and error and the results are not measured in the same way as traditional processes. Such routines are performative in nature (Pentland and Feldman, 2003) and generate innovation.

However, the experiments - even when they are successful - are not repeated or applied in similar situations, which shows that the embedding of individual knowledge into organizational knowledge - arising from these new experiences and based on these innovative practices and routines - is very small. Indeed, it seems that organizations feature low capability, through individuals and managers, to integrate them within the established organizational processes. Respondents point to the upper management's expedient vision: the incompatibility of adopting innovations subject to risk, trial-and-error learning, and uncertain time of adoption against the pressure for short-term results and objective goals, in addition to the lack of long-term entrepreneurial vision and fear of risk-taking. It was noted that emergent innovative processes address subjective aspects of the tasks, which are subsidiary, intangible and difficult to measure in terms of conventional HR practices, such as quality, image, values, and involvement. Whenever possible, leadership chooses to adopt the routine and comfort of measurable results, thereby reproducing the status quo.

\subsection{The emerging conceptualizations of organizational routines}

\subsection{Compliance routine}

The strictest OR concept describes routines as descriptive guides in the processes of compliance for the organization's operations, especially regarding compliance with legal and regulatory requirements. They include standard operating procedures (SOP) related to certifications such as ISO, Best Practices, and policies for compliance, quality (TQM) or safety. The context is inevitably associated with manufacturing environments or organizations in highly regulated industries.

The routine is "handed down from headquarters" and/or originates from "the department in charge of establishing these processes." It is strongly structured, disseminated, and may not be questioned; it permeates the reality of the organization and even its nonmanufacturing activities. It translates into the logic of thinking about its operations. Routines thus include practices, mindset, behaviors and control of the organization's results for the organization. Their nature is purely ostensive (Feldman \& Pentland, 2003). At most, the compliance routine may unfold as a translated routine (see below) to comply with local regulations.

"I think that when you deal with issues of large and multinational companies, you deal with legal issues. And, when you deal with inspection issues related to legislation or audits, internal or aimed at certifications, ISO, Good Practices, Quality ... You end up following a little book, a guide to meet the goal of the certification or inspection ... And 
many things that you could execute better, you end up not being able to. (Respondent 11)

Therefore, this view of ORs is related to the traditional approach (Cyert \& March, 1963; March \& Simon, 1958; Nelson and Winter, 1982; Simon, 1947) and may be defined as a capabilities stream (Parmigiani \& Howard-Grenvolle, 2011). Such a view comprises all activities within a single entity, encased in a black box; it focuses on organizational performance and considers the subjects as the operative part, as designed by the routine.

According to the view of the sociology of association (Latour, 2012), routine itself is an actor that mediates how subjects should perform their activities, it interprets how they should behave, what they should value. Routine also plays the role of the dominant controller. Due to its operational nature, it becomes the means to replicate activities and to measure results and performance (Friels \& Larty, 2013).

The compliance routine was found in multinational organizations, in organizations with a centralized management, and in those that disseminate their culture and values. Innovative and generative knowledge are hardly embedded in the compliance routine and dominant thinking actually doesn't even take that aspect in account. This routine is present in the descriptive categories of Application at Work and Consideration of Work/Individual.

\subsubsection{Certainty routine}

The concept of the certainty routine dismisses the idea that routines, practices or administrative processes need to be formalized to establish how the organization should perform its activities, especially in environments that hardly structure and formalize policies and rules, but which feature a high degree of centralized decision-making. According to that concept, routine (which is supposed to be an organizing element of corporate life) is presented as a coordinating element that controls and structures organizational reality. However, it doesn't depend on legal and regulatory aspects.

It deals with the daily aspects of a company, establishes not only the processes of all activities, but also creates and ensures the position of individuals (and their power and status), how to assess results and performance, thereby controlling the recognition system of the other members. That routine may be established by the headquarters or arise from the need to coordinate/control a given activity. In the latter case, the area that owns the routine proposes it - usually based on benchmarking by other companies - as a way of being endorsed. Therefore, rarely does the routine emerge from work in the way work is performed, i.e., in a performative manner; the routine is almost always implemented. The routine may even occasionally originate in a performative way, but once established, it becomes ostensive (Feldman \& Pentland, 2003), since it is hosted by the interested area and ensures certain positions within the organization.

"My contribution is currently to turn the processes more cohesive, to actually make routines, because when you design processes, things flow better, faster and more accurately. [The organization] enters an industrial, manufacturing stage... it therefore follows a sequence, it goes with the flow. [...] in my area, HR, we have been spending time creating great things ... now, we are putting these things into control. Currently, I need to get control of training. I must have control of training and remuneration, because to promote someone, I need these two systems to talk to each other. I need to know the matrix of information that this individual made at the [organization] so that I can handle his succession, either laterally or vertically ... Finally, systems have been created and now I need them to talk to each other. And for that to happen, I need to have processes." (Respondent 4)

The certainty routine always needs the formal authorization of the leadership or top management to be imported, developed by benchmarking or deployed. Furthermore, the 
time allotted to these activities is defined by the leadership or upper management, regardless of the need or urgency of individuals. The aspects related to the political process of the organization, expressed through routine, its implementation and maintenance are visible (Friesl \& Larty, 2013). This may be one of the routine's motivations to ensure the status and position of certain organizational members. The routine as a political process, which even acts as an artifact, emerges very strongly in the conception of Transformation of Work and the Individual.

This concept contains a traditional view (Cyert \& March, 1963; March \& Simon, 1958; Nelson \& Winter, 1982; Simon, 1947) and reveals the presence of the stream of capabilities (Parmigiani \& Howard-Grenvolle, 2011), similarly to the concept of the compliance routine. It is just as difficult for new knowledge to emerge from action, as it's not valued knowledge, let alone to establish itself within routines.

The certainty routine was found in national organizations featuring nonprofessional management, in medium-sized multinationals with little structure or formalization of activities and in very hierarchical companies run by centralized management. The certainty routine is present in the descriptive categories of Consideration of Work/Individual and Transformation of Work/ Individual, and to a lesser extent in Application at Work.

\subsubsection{Translated routine}

The concept of the translated routine introduces precisely the concept of flexibility and adaptation of the routine to contextual circumstances of the organization. Such flexibility may occur formally, in a process of adapting the routine to the local situation, or informally, in a process adapting to action, which ends up by incorporating the way of doing things into the routine.

In the first case, the formal adaptation of the routine seeks to comply with the rules, regulations and local laws. It is, in a way, an extension of the compliance routine. In such a case, headquarters is still the center of practices, but there is an understanding that the local contexts require different processes or modes of executing processes. However, there is still a strong coordinative bias and as soon as the routine is translated, it becomes ostensible (Feldman \& Pentland, 2003) in the normative sense of constraining different ways of working in the organization. The routine is assigned to the descriptive category of Application at Work, as a result of the compliance routine.

In the second case, it may result from work in routine activities, where certain tasks don't apply or no longer make sense. After a flexible, performative period that allows working around these points that don't fit the context, the routine is revisited and revised. It is assigned to the descriptive category Consideration of Work/Individual.

"Here, too, I've gained experience in many other human resources processes and procedures. I implemented several of them, here: we take what the company has that's global, but which needs to be adapted to the location ... because they are regionalities, different realities, hence, we implement ... I've already made progress, too, in implementing procedures, reviewing processes and in implementing improvements." (Respondent 11)

\footnotetext{
"From a standpoint of HR, the company has its own policies which we call corporate policies and we have the legislation [...] which doesn't always meet the one headquarters has. Thus, some things that existed as a standard were adopted with the required adaptation. This is always necessary. (Respondent 3).
}

Although the idea of flexibility has been introduced into routines based on work practice, the current concept still doesn't characterize the stream of routine-as-practice (Parmigiani \& Howard-Grenville, 2011). Both streams, the one of routine as capability and the one of routine as practice assume that routines rely on both a static and an evolutionary aspect, as well as on 
the relevance of the contexts for their operation. However, the mere adaptation of the routine does not characterize it from a purely performative perspective.

\subsubsection{Innovation routine}

Refers to a more flexible concept of routine, according to which it emerges from action and features a performative nature (Feldman $\&$ Pentland, 2003). Innovation routine arises from organizational members' perception that the current process is not the most appropriate one for the situational context of the organization or area involved and that it therefore must be revised based on a new point of view or entirely recreated. A perceived gap may also occur due to the absence of a certain process. Professionals understand that no ready solution or model exists, or that there may be better answers regarding the activity in question.

In any case, routine results from the action of working collectively and somehow encompasses collective knowledge for that situation. The very creation of the activity that involves the innovation routine is a learning process, a consequence of the organization's way of thinking. It's no coincidence, then, that the innovation routine is present in the descriptive categories Self-realization at Work and Emerging Creation for Life.

\footnotetext{
"We had a discussion yesterday ... we stayed here until two a.m. to go over the targets, when the year ends ... I told [the manager] "This process isn't viable ... It's one thing to do performance reviews when the company has two hundred people. Now there are two thousand! You can't sit down with each one and ask them 'tell me what you did', because the guy puts the target into the system and then, how does he prove he has the evidence of the project? I said, "It won't do any longer ... [...] We really have to rethink what we're doing, how we're doing it. The company has been expanding a lot in a short time." (Respondent 5)
}

Unlike previous concepts, the innovation routine is not intended to coordinate organizational life rigidly or to monitor individual performance.
Its intention is to establish the very practices and ways of working, which can therefore measure the practices and performances (in some cases, according to the conception of Self-realization at Work), but not necessarily (according to the conception of Emerging Creation for Life). As routine results from action, as a part of its situational nature, it is subject to questioning, change, and recreation.

Paradoxically, it is not necessarily knowledge created by new ways of conducting activities that will be embedded in routines. As discussed in the conception of Emerging Creation for Life, several innovative processes were incorporated into organizational practice, which is due to pressure for short-term results, the difficulty of organizations to learn from the new and the fear of taking risks that may result from changing the way activities are performed. It is appropriate here to take up once again the model of performative routines by Feldman (2000) according to which the cycle of updating the routine involves a series of actions that require addressing noncompliance, expanding operations, and hard work.

The innovation routine is part of the routine-as-practice stream (Parmigiani \& Howard-Grenville, 2011), according to which human action, located in a given specific context, produces the subjects' actions on routines, if not on the routine itself. It was found in multinational companies and large domestic companies run by professional management that feature a decentralized management model, a high degree of autonomy and a low degree of hierarchy.

Figure 2 consolidates the conceptions of valuing knowledge in terms of definition, nature of knowledge, conceptualizations of routines found therein, and the organizational context in which it operates. As for this last dimension, in the discussion that follows below, the paper suggests that it functions as a structural pattern for individuals in the way they conceive knowledge of value and their consequent attitudes to embed it into organizational routines. 


\begin{tabular}{|c|c|c|c|c|c|c|}
\hline 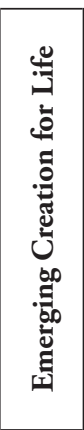 & 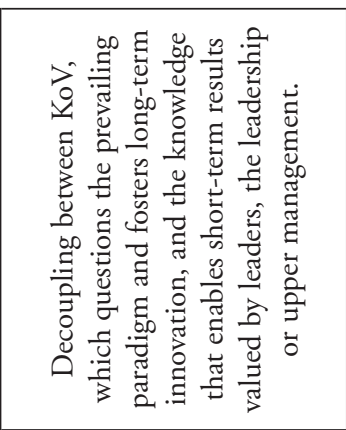 & 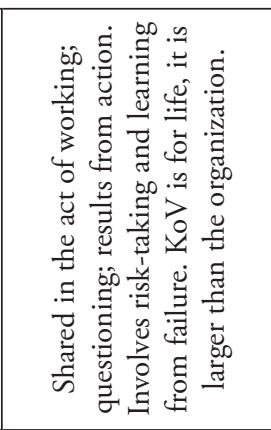 & 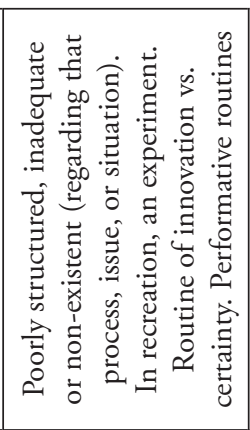 & 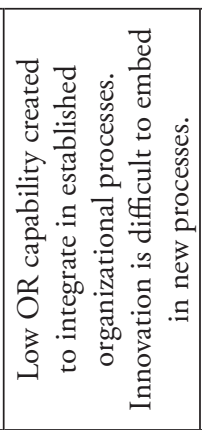 & 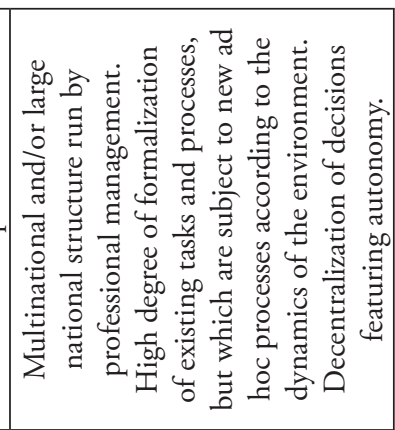 & 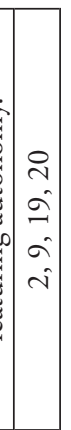 \\
\hline 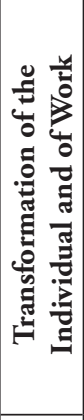 & 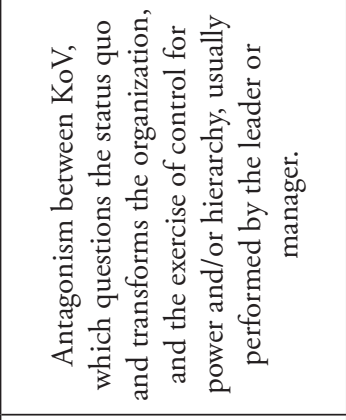 & 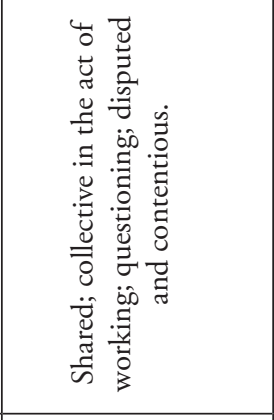 & 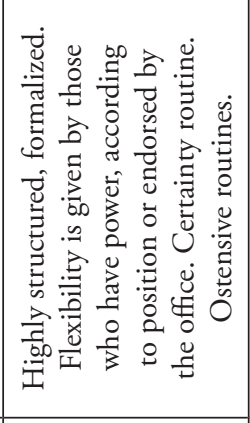 & 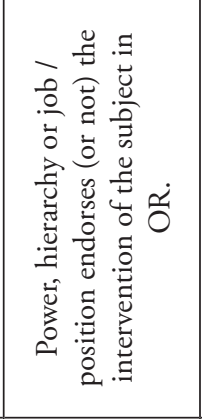 & 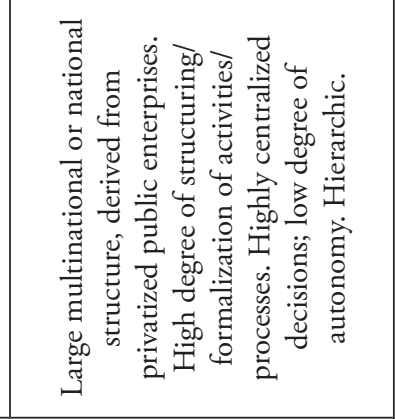 & 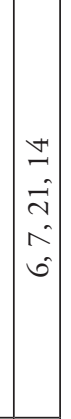 \\
\hline 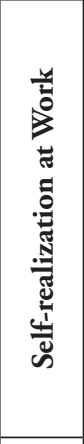 & 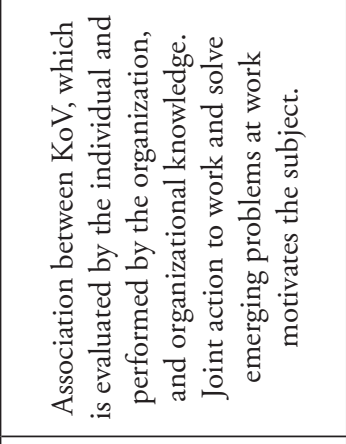 & 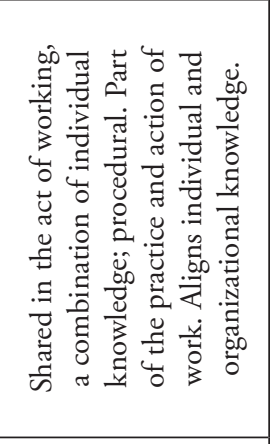 & 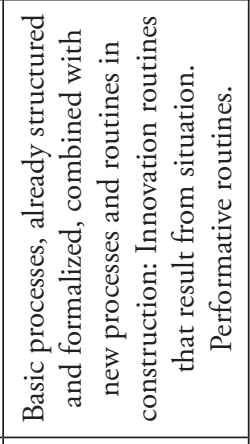 & 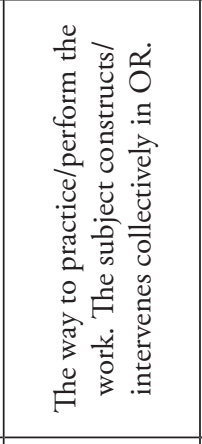 & 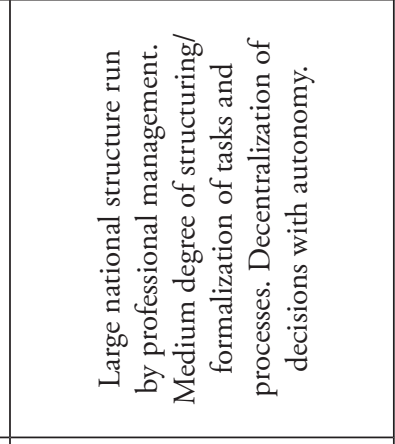 & 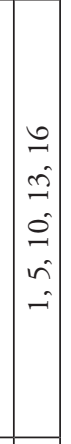 \\
\hline 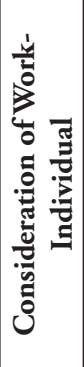 & 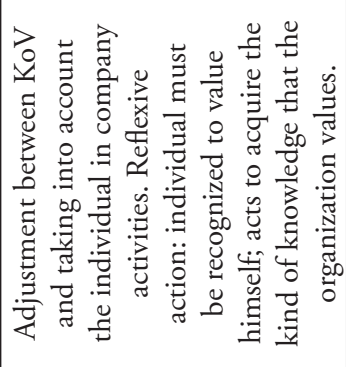 & 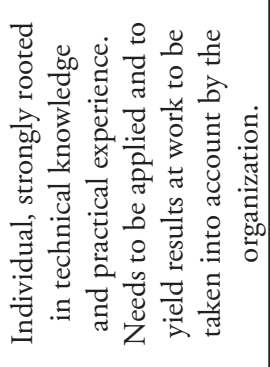 & 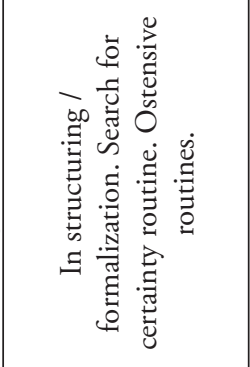 & 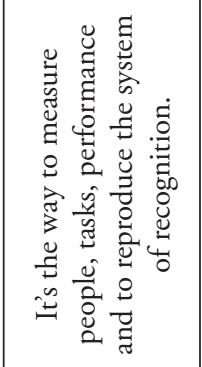 & 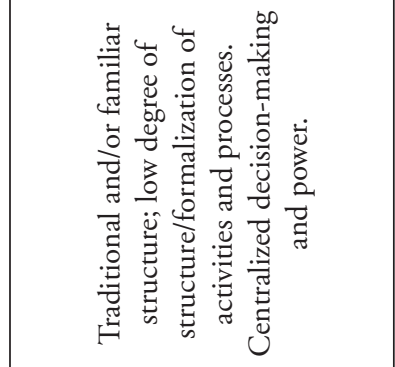 & 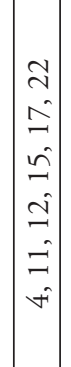 \\
\hline 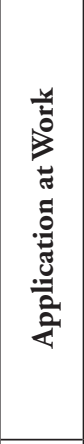 & 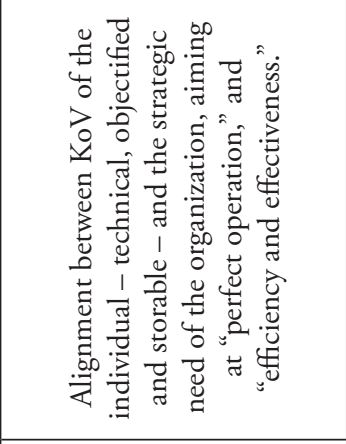 & 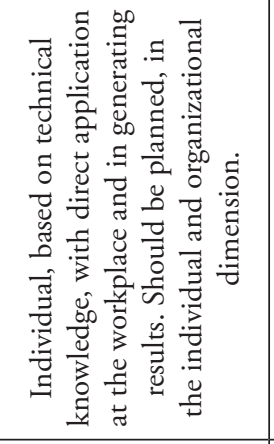 & 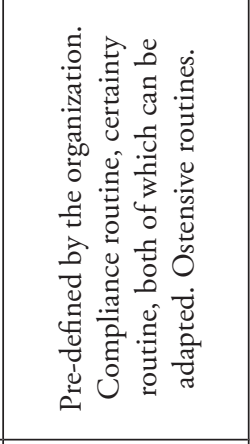 & 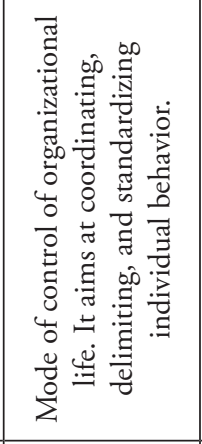 & 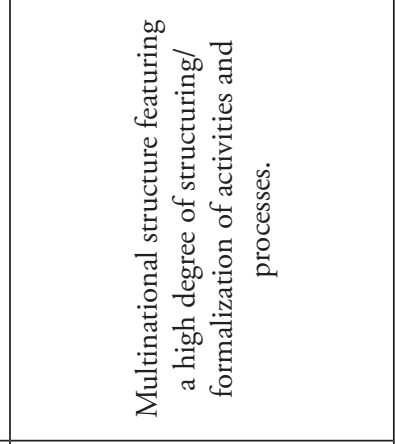 & $\begin{array}{c}\infty \\
- \\
\infty \\
m\end{array}$ \\
\hline 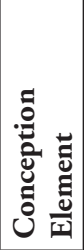 & 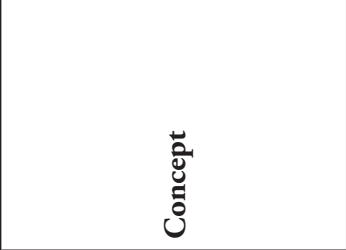 & 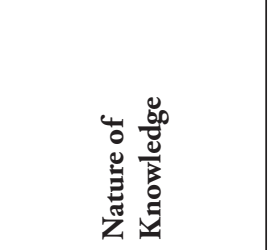 & 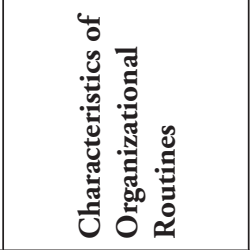 & 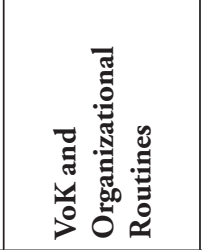 & 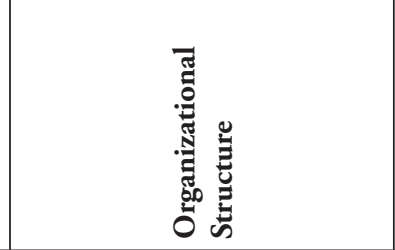 & $\begin{array}{l}\frac{0}{0} \\
\frac{0}{0} \\
0 \\
5 \\
5\end{array}$ \\
\hline
\end{tabular}




\section{Discussion about valuing of knowledge and its embedding into organizational practice and routines}

Taking up once again the application of valued knowledge into the practices and ORs in each category, it was found that the application and embedding of valued knowledge in work routines and practices assumes different gradations for each conception - from almost zero or very low (in the Application at Work), to very fluid and continuous (in Self-realization at Work), including control explicitly mediated by leadership and upper management in other conceptions.

Self-realization at Work was the only category to which the individual and collective contribution of emerging knowledge of practice and action resulted in the organization's own processes and activities, which were consistently embedded in the ORs in a more performative way (Feldman, 2000; Feldman \& Pentland, 2003). In turn, the conception Emerging Creation for Life is characterized by the contribution of individual knowledge resulting from actions to organizational activities, where innovative content encourages breaking paradigms. However, these were isolated experiences; little of what was experienced and learned by the individual and the collective was embedded into organizational routines, which shows the low capacity of the current model and of the organizational practices to absorb, learn, and internalize the experience. It should be noted that regarding the categories Application at work, Consideration Work/Individual and Transformation of Work/Individual, there are indeed contributions to organizational practices; they restrict themselves to adapting or introducing practices and routines that (i) are more ostensive (Feldman, 2000; Feldman \& Pentland, 2003); and (ii) preserve the way the organization works, i.e., generating new or additional performance controls and addressing the demands defined and authorized by the leadership. Routines meet the needs of the organization, but not those of individuals and the use of their knowledge at work.

However, it is suggested that all conceptions found are intrinsically determined by the 'structural patterns' of that arrangement (Latour, 2012). The study suggests that the structural context of which the organization is part - centralized decisions or not, hierarchical or not, dependent on national / multinational / privatized / family origin - end up creating the social / spatial context that shapes the structural pattern, defining the way how individuals think the value of knowledge and how to embed it into organizational practices and routines (Friesl \& Larty, 2013; Pentland \& Hærem, 2015). Social construction produces the (i) collective in which the individual is immersed, (ii) valued knowledge, and (iii) the rules of living of that collective (Latour, 2012; Pentland \& Hærem, 2015), thereby shaping the relations of exchange and embedding of valued knowledge in the individual/organizational interaction, according to certain structural patterns that are inherent to the arrangement.

Therefore - if the phenomenon of individual knowledge and organizational knowledge actually may be observed in a separate and fragmented way - it can generally be inferred that the contribution of individual and collective knowledge (built through shared action) to organizational knowledge, through embedding in ORs, seems to be very limited in its content and controlled in scope due to either the structural pattern (Latour, 2012), or the pattern of action (Pentland \& Hærem, 2015). In all conceptions, little of the individual or collective knowledge contributes to modify, create or compose something that contributes in a new / thought-provoking / challenging way to the knowledge embedded in existing ORs; this observation is consistent with the findings by Bertels, Howard-Grenville and Pek (2016). This doesn't mean that contributions don't occur or are no longer accepted, but it is suggested that 
significant contributions (from the point of view of the perception of value by individuals that generate impacts on organizational practice and help to rethink the organization and its way of working) are unlikely to occur.

Thus, the study suggests that significant changes in organizational practices and routines seem to continually come from the upper management and the leadership, i.e., the key mediators of the organization (Latour, 2012) who authorize, sponsor, require or allow changes to and/or inclusions of practices and routines into organizational life. It turns out that ORs reflect and, at the same time, compose the structural pattern of the organization, along with the organizational context, hierarchy, decisionmaking, organizational culture, leadership and upper management, and other aspects that make up that collective (Pentland \& Hærem, 2015). In addition to the existing ostensible or performative character of routines (Feldman 2000, Feldman \& Pentland, 2003), the findings corroborate the vision by Friesl \& Larty (2013) who define ORs as a process of politics and power that results in implications for the interests of the various actors involved in the routine and its approval.

\section{Conclusion}

The purpose of this study was to analyze the impact of different modes (conceptions) by which organizational members perceive and experience valuing of knowledge in the context of work on the subsequent embedding of knowledge into organizational routines. Its contribution to business studies develops from the discussion on the limited use of individual knowledge in collective knowledge of the organization, due to the difficulty to harness the full use of human capabilities for the benefit of the organization, notably in the models of management and structure found in the organizations surveyed. Therefore, this study analyzes how the existing, conventional organizational models are perceived by individuals, generating real consequences in terms of hampering the embedding of knowledge of value into organizational routines.

The organizations in which the individuals are inserted and that composed the sample are traditional, active in conventional markets, feature organizational structures that are still based on more or less hierarchical and centralized models, and that are inserted in partnership networks. In those models, the survey showed a dominant, structural pattern of logic built by the major actors and rebuilt by everyone in the arrangement, which shapes the way of thinking, being, and acting in that context. The study inquires the real possibility of adopting open, transparent, decentralized management models that are participatory and shared among organizational members and that facilitate the inclusion of individuals in the recursive construction of the organization and of their knowledge embedded in practices. It questions the knowledge already established in that context and defined prior to the situation experienced. Hence, this paper reveals that the structure shapes the individual and his practices at the organization. It thus suggests that other forms of contemporary configurations - cooperative, hybrid and social co-management (Jay, 2013; Tracey, Phillips, \& Jarvis, 2011), holacratic in structure (Robertson, 2007; 2015), entrepreneurial, collaborative in nature, or partnership networks (CamarinhaMatos \& Afsarmanesh, 2006; Kreiner \& Schultz, 1993; Powell, 2003) and innovative (Baldwin \& von Hippel, 2011; Kreiner \& Schultz, 1993) are necessary and would greatly benefit human capital in the use of its potential, fostering the emergence of what is referred to, in this study, as innovation routines.

Thus, the first limitation of this work is that the sample was limited to HR. Conceptions of valuing knowledge may be shaped differently in other organizational areas, especially if they are related to the core business of the organization, since the subjects are immersed in another collective arrangement that might evoke a different form of structuring pattern. As a result, inserting such knowledge into organizational 
routines could proceed differently, given the urgency of the application of knowledge to the organization's core products.

Another important limitation relates to the organizations in which the individuals participate. The sample did not include organizations from other industries, such as the creative sector, the cooperative economy, or those that strongly focus on innovation and technology, such as the electronics and computing industry. In these types of organization, the importance of innovation and creativity seem to require new contemporary configurations that suggest different ways of conceiving organizational practices and routines.

It is therefore appropriate to suggest that additional phenomenographic comparative research be conducted with professionals from other corporate areas, especially those that are related to the core business, to include new conceptions of ways of understanding valuing of knowledge and its embedding in ORs. An additional phenomenographic study with individuals from organizations featuring contemporary structures and configurations is also suggested to analyze whether different conceptions emerge from a new structural pattern. Above all, researchers should continue to study the embedding of ORs into different contexts and structural patterns, which is reinforced by the findings by Bertels, Howard-Grenville \& Pek (2016) and Pentland \& Hærem (2015). Finally, researchers should expand the line of research of organizational knowledge by including a greater dimension of wisdom in organizational studies that illuminate and transform the forms, models and paradigms of how actors think: individuals and organizations.

\section{References}

Akerlind, G. S. (2005). Learning about phenomenography: Interviewing, data analysis and the qualitative research paradigm. In J. Bowden., \& P. Green (Orgs.), Doing Developmental Phenomenography (Qualitative Research Methods Series), (pp. 63-73). Melbourne: RMIT University Press.
Antonacopoulou, E. P. (2006). The relationship between individual and organizational learning: New evidence from managerial learning practices. Management learning, 37(4), 455-473.

Argote, L., \& Ren, Y. (2012). Transactive memory systems: A microfoundation of dynamic capabilities. Journal of Management Studies, 49(8), 1375-1382.

Baldwin, C., \& von Hippel, E. (2011). Modeling a paradigm shift: From producer innovation to user and open collaborative innovation. Organization Science, 22(6), 1399-1417.

Barney, J. B. (1991). Firm resources and sustained competitive advantage. Journal of Management, 17(1), 99-120.

Barney, J. B. (1996). Gaining and sustaining competitive advantage. Massachusetts: AddisonWesley Pub. Co.

Bertels, S., Howard-Grenville, J., \& Pek, S. (2016). Cultural molding, shielding, and shoring at Oilco: The role of culture in the integration of routines. Organization Science, 27(3), 573 - 593. doi.org/10.1287/orsc.2016.1052

Brown, J. S., \& Duguid, P. (1991). Organizational learning and communities-of-practice: Toward a unified view of working, learning, and innovation. Organization science, 2(1), 40-57.

Camarinha-Matos, L. M., \& Afsarmanesh, H. (2006). Collaborative networks: Value creation in a knowledge society. Knowledge enterprise, IFIP, 207, 26-40.

Cyert, R. M., \& March, J. G. (1963). A behavioral theory of the firm. New Jersey: Prentice-Hall.

Dewey, J. (1922). Human nature and conduct. Massachusetts: Courier Corporation.

Eisenhardt, K. M., \& Martin, J. A. (2000). Dynamic capabilities: What are they? Strategic management journal, 21(10-11), 1105-1121. 
Feldman, M. S. (2000). Organizational routines as a source of continuous change. Organization science, 11(6), 611-629.

Feldman, M. S., \& Orlikowski, W. J. (2011). Theorizing practice and practicing theory. Organization Science, 22(5), 1240-1253.

Feldman, M. S., \& Pentland, B. T. (2003). Reconceptualizing organizational routines as a source of flexibility and change. Administrative science quarterly, 48(1), 94-118.

Felin, T., Foss, N. J., Heimeriks, K. H., \& Madsen, T. L. (2012). Microfoundations of routines and capabilities: Individuals, processes, and structure. Journal of Management Studies, 49(8), 1351-1374.

Friesl, M., \& Larty, J. (2013). Replication of routines in organizations: Existing literature and new perspectives. International Journal of Management Reviews, 15(1), 106-122.

Gherardi, S. (2000). Practice-based theorizing on learning and knowing in organizations. Organization, 7(2), 211-224.

Grant, R. M. (1996). Toward a knowledgebased theory of the firm. Strategic Management Journal, 17(S2), 109-122.

Jay, J. (2013). Navigating paradox as a mechanism of change and innovation in hybrid organizations. Academy of Management Journal, 56(1), 137-159.

Kreiner, K., \& Schultz, M. (1993). Informal collaboration in $\mathrm{R} \& \mathrm{D}$ : The formation of networks across organizations. Organization studies, 14(2), 189-209.

Latour, B. (2012) Reagregando o social: Uma introdução à teoria do ator-rede. Salvador: EDUFBA/EDUSC.

Lave, J., \& Wenger, E. (1991). Situated learning: Legitimate peripheral participation. Cambridge: Cambridge University Press.
March, J. G., \& Simon, H. A. (1958). Organizations. Oxford, England: Wiley.

Marton, F. (1981). Phenomenography-describing conceptions of the world around us. Instructional Science, 10(2), 177-200.

Marton, F., \& Booth, S. A. (1997). Learning and awareness. Mahwah: Lawrence Erlbaum Inc. Publishers.

Nag, R., Corley, K. G., \& Gioia, D. A. (2007). The intersection of organizational identity, knowledge, and practice: Attempting strategic change via knowledge grafting. Academy of Management Journal, 50(4), 821-847.

Nelson, R. R., \& Winter, G. (1982). An evolutionary theory of economic change. Cambridge, MA: Harvard University.

Nonaka, I. (1994). A dynamic theory of organizational knowledge creation. Organization Science, 5(1), 14-37.

Nonaka, I., \& Takeuchi, H. (1997) Criação de conhecimento na empresa: Como as empresas japonesas geram a dinâmica da inovação. (7a ed.), Rio de Janeiro: Campus.

Orlikowski, W. J. (2002). Knowing in practice: Enacting a collective capability in distributed organizing. Organization Science, 13(3), 249-273.

Parmigiani, A., \& Howard-Grenville, J. (2011). Routines revisited: Exploring the capabilities and practice perspectives. The Academy of Management Annals, 5(1), 413-453.

Patriotta, G. (2003) Organizational knowledge in the making: How firms create, use and institutionalize knowledge. New York: Oxford University Press.

Pentland, B. T. (1995). Grammatical models of organizational processes. Organization Science, 6(5), 541-556.

Pentland, B. T., \& Hærem, T. (2015). Organizational routines as patterns of action: Implications for organizational behavior. 
Annual Review of Organizational Psychology and Organizational Behavior, 2(1), 465-487.

Powell, W. (2003). Neither market nor hierarchy. The sociology of organizations: Classic, contemporary, and critical readings, 315, 104-117.

Prahalad, C. K., \& Hamel, G. (1990) The core competence of the corporation. Harvard Business Review, 68(3), 79-91.

Robertson, B. J. (2007). Organization at the leading edge: Introducing holacracy ${ }^{\mathrm{Tm}}$ Evolving Organization. Integral Leadership Review, 7(3). Source: http://www.integralesleben. org/ fileadmin/user_upload/images/DIA/Flyer/ Organization_at_the_Leading_Edge_200706_01.pdf

Robertson, B. J. (2015). Holacracy: The revolutionary management system that Abolishes hierarchy. Londres: Penguin.

Sandberg, J. (2000). Understanding human competence at work: An interpretative approach. Academy of management journal, 43(1), 9-25.

Simon, H. A. (1947). Administrative behavior. New York: Free Press.
Swart, J. (2011). That's why it matters: How knowing creates value. Management Learning, 42(3), 319-332.

Szulanski, G. (1996). Exploring internal stickiness: Impediments to the transfer of best practice within the firm. Strategic Management Journal, $17(\mathrm{~S} 2), 27-43$.

Teece, D. J. (2007). Explicating dynamic capabilities: The nature and microfoundations of (sustainable) enterprise performance. Strategic Management Journal, 28(13), 1319-1350.

Teece, D. J., Pisano, G., \& Shuen, A. (1997). Dynamic capabilities and strategic management. Strategic Management Journal, 18(7), 509-533.

Tracey, P., Phillips, N., \& Jarvis, O. (2011) Bridging institutional entrepreneurship and the creation of new organizational forms: A multilevel model. Organization Science 22(1), 60-80.

Zollo, M., \& Winter, S. G. (2002). Deliberate learning and the evolution of dynamic capabilities. Organization Science, 13(3), 339-351.

\section{About the authors:}

1. Andréa Cherman, $\mathrm{PhD}$ in Business Administration, Pontifical Catholic University of Rio de Janeiro (PUC-Rio), Brazil. Email: acherman@prof.iag.puc-rio.br.

2. Sandra Regina da Rocha-Pinto, PhD in Education, Pontifical Catholic University of Rio de Janeiro (PUC-Rio), Brazil. Email: sanpin@iag.puc-rio.br.

\section{Contribution of each author:}

\begin{tabular}{lcc}
\hline Contribution & Andréa Cherman & Sandra Regina Rocha-Pinto \\
\hline 1. Definition of research problem & $\sqrt{ }$ & $\sqrt{ }$ \\
2. Development of hypotheses or research questions (empirical studies) & $\sqrt{ }$ \\
3. Theoretical foundation / Literature review & $\sqrt{ }$ \\
4. Definition of methodological procedures & $\sqrt{ }$ \\
5. Data collection & $\sqrt{ }$ \\
6. Analysis and interpretation of data & $\sqrt{ }$ \\
7. Critical revision of the manuscript & $\sqrt{ }$ \\
8. Manuscript writing & $\sqrt{ }$ & $\sqrt{ }$ \\
\hline
\end{tabular}

